\title{
A study of the structure of the pindolol based on infrared spectroscopy and natural bond orbital theory
}

\author{
Ricardo A.E. Castro ${ }^{\mathrm{b}, *}$, João Canotilho ${ }^{\mathrm{b}}$, Sandra C.C. Nunes ${ }^{\mathrm{a}}$, \\ M. Ermelinda S. Eusébio ${ }^{a}$, J. Simões Redinha ${ }^{a}$ \\ a Chemistry Department, University of Coimbra, Coimbra, Rua Larga 3004-535, Portugal \\ ${ }^{\mathrm{b}}$ Faculty of Pharmacy, University of Coimbra, Coimbra, Rua do Norte 3000-295, Portugal
}

\section{A R T I C L E I N F O}

Article history:

Received 31 July 2008

Received in revised form

18 November 2008

Accepted 23 November 2008

\section{Keywords:}

Pindolol

$\beta$-Blocker

Infrared spectroscopy

Natural bond orbital (NBO) analysis

Density functional theory

\begin{abstract}
A B S T R A C T
Beta-adrenoceptor-blocking agents ( $\beta$-blockers) are on the list of the top selling drugs. Pindolol is a representative of this type of compound, either from the structural point of view, or as reference for comparison of the pharmacokinetic properties of the $\beta$-blockers. A study of the pindolol structure based on infrared spectroscopy and natural bond orbital (NBO) theory is the main aim of the present research.

FTIR spectra of the solid pindolol were recorded from 4000 to $400 \mathrm{~cm}^{-1}$, at temperatures between 25 and $-170^{\circ} \mathrm{C}$. For spectral interpretation, the theoretical vibrational spectra of the conformer present in the solid was obtained at the B3LYP/6-31G* level of theory. NBO analysis of the reference conformer, before and after optimization, was carried out at the same level of theory referred above.

Characteristic absorption vibrational bands of the spectra of solid pindolol and of the isolated conformer were identified. Intra- and intermolecular interactions in pindolol were confirmed by the frequency shift of the vibrational modes and by the NBO theory.

A detailed molecular picture of pindolol and of its intermolecular interactions was obtained from spectroscopy and NBO theory. The combination of both methods gives a deeper insight into the structure. (c) 2008 Elsevier B.V. All rights reserved.
\end{abstract}

\section{Introduction}

Pindolol, 1-(1H-indol-4-yloxy)-3-(isopropylamino)-2-propanol (see Fig. 1 for structure and atom numbering), is widely used as a $\beta$-blocker in hypertension treatment [1].

Its molecular structure consists of an indole group to which an isopropylaminopropoxy chain is attached. This side chain is a common part to many $\beta$-blockers and only slightly differs from a few others in which isobutyl replaces isopropyl [2]. The aromatic fragment also plays an important role conferring certain specific pharmacokinetics properties to pindolol $[3,4]$.

The study of the pindolol structure is of unquestionable interest because of its widespread use as $\beta$-blocker in medical practice. The only relevant information available on the structure involves $\mathrm{X}$-ray diffraction data [5]. The aim of the present work is to interpret the structural features using IR spectroscopy and NBO analysis. The former is an excellent method to obtain evidence of intraand intermolecular interactions through their effects on the vibrational modes of the molecule while the latter allows a description of the electronic structure of the molecule in terms of natural bond orbitals.

\footnotetext{
* Corresponding author. Tel.: +351 239852568; fax: +351 239852569

E-mail address: rcastro@ff.uc.pt (R.A.E. Castro).
}

The interpretation of the infrared spectra either in terms of band assignment or the appraisal of the effects of intermolecular forces requires information on the spectrum of the isolated molecule. It is not possible to obtain such a spectrum for pindolol experimentally since the compound has very low solubility in inert solvents together with a low vapour pressure, not allowing its determination in the gas phase or by matrix isolation technique. Instead, the reference spectrum has been calculated by optimizing the conformation obtained by X-ray diffraction. The structure optimization was performed at the DFT level of theory using the B3LYP functional $[6,7]$ and the $6-31 \mathrm{G}^{*}$ basis set.

The NBO analysis at B3LYP/6-31G* level was performed on two structures. One is derived from single point calculation, hereafter designated as the single point structure; the other corresponds to the optimized structure, and is designated as such. The NBO output for the former provides information on the structure of the conformer present in solid pindolol, while the second gives information on the isolated molecule, i.e. the structure of the later conformer free from intermolecular interactions.

\section{Materials and methods}

The $(R, S)$-pindolol used in the spectroscopic measurements was supplied by Sigma-Aldrich as 99\% pure. Purity was checked by HPLC 


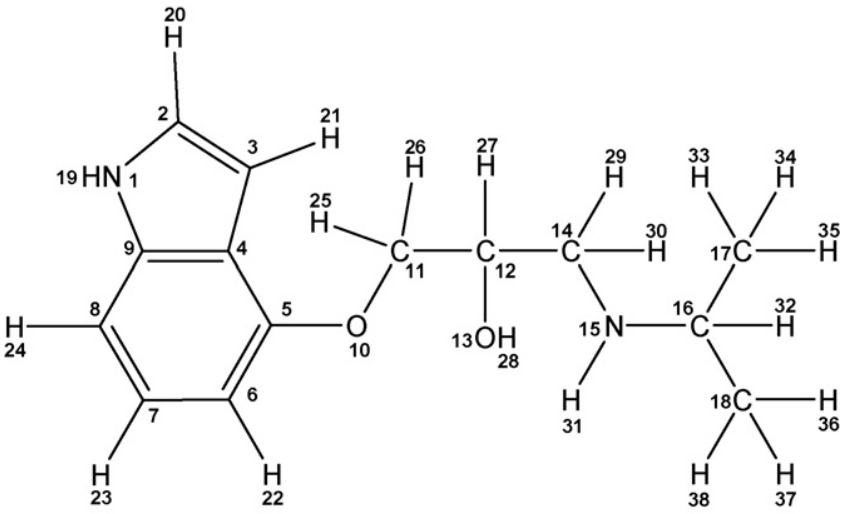

Fig. 1. Pindolol, 1-(1H-indol-4-yloxy)-3-(isopropylamino)-2-propanol.

and no extra peaks were observed. The substance was used without any further purification.

The spectra were recorded between -170 and $25^{\circ} \mathrm{C}$ in $10^{\circ} \mathrm{C}$ intervals with a FTIR spectrophotometer (Thermo Nicolet, IR300, USA) using the $\mathrm{KBr}$ pellet technique. Sixteen scans were run to collect each spectrum at a resolution of $1 \mathrm{~cm}^{-1}$.

The cell used had sodium chloride windows and temperature control device supplied by Graseby Specac. To avoid water vapour condensation, the cell compartment was kept under vacuum. The temperature control inside the cell was approximately $\pm 0.5^{\circ} \mathrm{C}$.

Spectra were also run on deuterated pindolol. Solid samples were maintained in equilibrium with D-methanol, 99.97\%-D, for $1 \mathrm{~h}$ at $60^{\circ} \mathrm{C}$ under an argon atmosphere. The liquid was then removed by evaporation at reduced pressure.

\section{Calculated infrared spectra}

The isolated molecule spectrum was obtained by optimizing the molecular conformation given by X-ray diffraction at the B3LYP/6$31 \mathrm{G}^{*}$ level using the Gaussian03W program [8]. No imaginary frequencies were found. The calculated vibrational frequencies were scaled by the recommended factor of 0.9613 [9]. The band assignment was performed by means of GaussianView [10] animation.

\section{NBO analysis}

The NBO analysis was performed with the NBO 5.0 program [11]. A short outline of the NBO segments used and of their structural meaning is presented below.

NBO theory allows the assignment of the hybridization of atomic lone-pairs and of the atoms involved in bond orbitals. These are important data in spectral interpretation since the frequency ordering is related to the bond hybrid composition.

Another useful chemical concept that can be interpreted through NBO theory is the interaction between orbitals. The electron delocalization from a filled high energy bond orbital or lone-pair into a low energy antibonding orbital stabilizes the conformation that maximizes the overlap of the orbitals participating in this interaction. Values of the energy $E_{i j^{*}}^{(2)}$, for the interaction between the filled, $i$, and vacant orbital, $j^{*}$, calculated by the second order pertubation theory are outputs from the NBO program.

An additional piece of information obtained from NBO analysis relates to the effect of the orbital interactions on the bond orientation. The rehybridization of the electron acceptor orbital D-H resulting from electron transfer from the lone-pair or donor group gives rise to a deviation of the $\mathrm{D}$ atom natural hybrid orbital orientation from that defined by the two nuclear centers. Information on such a deviation is also valuable from the structural point of view.
Table 1

Calculated wavenumbers, intensities, and approximate description of the pindolol spectra bands. Threshold for $I: 3 \mathrm{~km} \mathrm{~mol}^{-1}$.

\begin{tabular}{|c|c|c|}
\hline Approximate description & $\bar{v} / \mathrm{cm}^{-1}$ & $I / \mathrm{km} \mathrm{mol}^{-1}$ \\
\hline$v(\mathrm{O} 13-\mathrm{H})$ & 3588 & 42.5 \\
\hline$v(\mathrm{~N} 1-\mathrm{H})$ & 3529 & 65.1 \\
\hline$\nu(\mathrm{N} 15-\mathrm{H})$ & 3354 & 2.9 \\
\hline$v(\mathrm{C} 2-\mathrm{H}), v(\mathrm{C} 3-\mathrm{H})$ i.p. & 3159 & 5.0 \\
\hline$v(\mathrm{C} 6-\mathrm{H})$ & 3103 & 12.8 \\
\hline$\nu(\mathrm{C} 7-\mathrm{H}), v(\mathrm{C} 8-\mathrm{H})$ i.p. & 3081 & 29.6 \\
\hline$v(\mathrm{C} 7-\mathrm{H}), v(\mathrm{C} 8-\mathrm{H})$ o.p. & 3065 & 3.4 \\
\hline$v_{\mathrm{a}}\left(\mathrm{C} 17-\mathrm{H}_{3}\right), v_{\mathrm{a}}\left(\mathrm{C} 18-\mathrm{H}_{3}\right)$ i.p. & 3005 & 57.0 \\
\hline$\nu_{\mathrm{a}}\left(\mathrm{C} 17-\mathrm{H}_{3}\right), \nu_{\mathrm{a}}\left(\mathrm{C} 18-\mathrm{H}_{3}\right)$ o.p. & 3000 & 19.6 \\
\hline$\nu_{\mathrm{a}}\left(\mathrm{C} 18-\mathrm{H}_{3}\right)$ & 2996 & 32.5 \\
\hline$v_{\mathrm{a}}\left(\mathrm{C} 17-\mathrm{H}_{3}\right)$ & 2988 & 34.4 \\
\hline$v_{\mathrm{a}}\left(\mathrm{C} 11-\mathrm{H}_{2}\right), v(\mathrm{C} 14-\mathrm{H})$ i.p. & 2959 & 70.6 \\
\hline$v_{\mathrm{a}}\left(\mathrm{C} 11-\mathrm{H}_{2}\right), \nu(\mathrm{C} 14-\mathrm{H})$ o.p. & 2948 & 10.1 \\
\hline$\nu_{\mathrm{s}}\left(\mathrm{C} 17-\mathrm{H}_{3}\right), \nu_{\mathrm{s}}\left(\mathrm{C} 18-\mathrm{H}_{3}\right)$ i.p. & 2932 & 9.9 \\
\hline$\nu_{\mathrm{s}}\left(\mathrm{C} 17-\mathrm{H}_{3}\right), \nu_{\mathrm{s}}\left(\mathrm{C} 18-\mathrm{H}_{3}\right)$ o.p. & 2926 & 28.5 \\
\hline$v_{\mathrm{s}}\left(\mathrm{C} 11-\mathrm{H}_{2}\right)$ & 2908 & 33.3 \\
\hline$v(\mathrm{C} 12-\mathrm{H})$ & 2897 & 30.7 \\
\hline$v(\mathrm{C} 14-\mathrm{H})$ & 2816 & 70.8 \\
\hline$v(\mathrm{C} 16-\mathrm{H})$ & 2792 & 67.6 \\
\hline$v(\mathrm{C} 4=\mathrm{C} 5), v(\mathrm{C} 7=\mathrm{C} 8)$ i.p. & 1606 & 17.3 \\
\hline$v(\mathrm{C} 4=\mathrm{C} 9), v(\mathrm{C} 6=\mathrm{C} 7)$ i.p. & 1579 & 77.1 \\
\hline$\delta(\mathrm{N} 1-\mathrm{H})$ & 1499 & 93.2 \\
\hline$\delta(\mathrm{N} 15-\mathrm{H})$ & 1486 & 23.7 \\
\hline$\delta\left(\mathrm{C} 17-\mathrm{H}_{3}\right), \delta\left(\mathrm{C} 18-\mathrm{H}_{3}\right)$ i.p., $\delta\left(\mathrm{C} 14-\mathrm{H}_{2}\right)$, & 1484 & 6.8 \\
\hline$\delta\left(\mathrm{C} 11-\mathrm{H}_{2}\right), \delta\left(\mathrm{C} 14-\mathrm{H}_{2}\right)$ i.p. & 1476 & 27.6 \\
\hline$\delta\left(\mathrm{C} 11-\mathrm{H}_{2}\right), \delta\left(\mathrm{C} 14-\mathrm{H}_{2}\right)$ o.p. & 1469 & 39.9 \\
\hline$\delta\left(\mathrm{C} 17-\mathrm{H}_{3}\right), \delta\left(\mathrm{C} 18-\mathrm{H}_{3}\right)$ i.p. & 1468 & 7.5 \\
\hline$\delta(\mathrm{N} 15-\mathrm{H}), \delta\left(\mathrm{C} 17-\mathrm{H}_{3}\right), \delta\left(\mathrm{C} 18-\mathrm{H}_{3}\right)$ o.p. & 1451 & 9.8 \\
\hline$\delta(C 7-H), \delta(C 8-H)$ i.p. & 1423 & 27.0 \\
\hline$\delta(\mathrm{O} 13-\mathrm{H}), v(\mathrm{C} 12-\mathrm{C} 14), \mathrm{w}\left(\mathrm{C} 11-\mathrm{H}_{2}\right), \mathrm{w}\left(\mathrm{C} 14-\mathrm{H}_{2}\right)$ i.p. & 1415 & 16.1 \\
\hline$\delta(\mathrm{N} 1-\mathrm{H}), v(\mathrm{C} 9-\mathrm{C} 1), v(\mathrm{C} 2-\mathrm{N} 1)$ i.p. & 1407 & 22.3 \\
\hline$\delta\left(\mathrm{C}-\mathrm{H}_{3}\right)$ umbrella i.p. & 1388 & 15.4 \\
\hline$\gamma(\mathrm{C} 12-\mathrm{H})$ & 1373 & 10.3 \\
\hline$\delta(\mathrm{N} 1-\mathrm{H}), v(\mathrm{~N} 1-\mathrm{C} 9), v(\mathrm{C} 4-\mathrm{C} 9), v(\mathrm{C} 8-\mathrm{C} 9)$ & 1350 & 108.0 \\
\hline$v(\mathrm{C} 16-\mathrm{H})$ & 1343 & 31.2 \\
\hline$v(\mathrm{C} 9-\mathrm{C} 4), v(\mathrm{C} 5-\mathrm{C} 4), v(\mathrm{C} 3-\mathrm{C} 4)$ & 1336 & 7.0 \\
\hline$\delta(013-\mathrm{H})$ & 1288 & 73.6 \\
\hline$\delta(\mathrm{C} 15-010)$ & 1271 & 128.9 \\
\hline $\operatorname{tw}\left(\mathrm{C} 14-\mathrm{H}_{2}\right), \delta(\mathrm{C} 12-\mathrm{H})$ & 1256 & 19.2 \\
\hline$\delta(\mathrm{N} 1-\mathrm{H}), \delta(\mathrm{C} 6-\mathrm{H}), \delta(\mathrm{C} 7-\mathrm{H}), \delta(\mathrm{C} 8-\mathrm{H})$ i.p. & 1230 & 124.5 \\
\hline $\operatorname{tw}\left(\mathrm{C} 11-\mathrm{H}_{2}\right)$ & 1225 & 71.8 \\
\hline$\delta(\mathrm{N} 1-\mathrm{H}), \delta(\mathrm{C} 2-\mathrm{H}), \delta(\mathrm{C} 3-\mathrm{H})$ i.p. & 1192 & 21.1 \\
\hline$v(\mathrm{C} 16-\mathrm{N} 15)$ & 1171 & 36.1 \\
\hline$\delta(\mathrm{N} 1-\mathrm{H}), \delta(\mathrm{C}-\mathrm{H})$ indole o.p. & 1116 & 75.0 \\
\hline$\rho\left(\mathrm{C} 11-\mathrm{H}_{2}\right), v(\mathrm{C} 14-\mathrm{N} 15)$ i.p. & 1095 & 17.7 \\
\hline$v(\mathrm{C} 11-\mathrm{C} 12)$ & 1083 & 26.1 \\
\hline$v(\mathrm{C} 2-\mathrm{N} 1)$ & 1071 & 44.8 \\
\hline$v(\mathrm{C} 2-\mathrm{N} 1), v(\mathrm{C} 16-\mathrm{N} 15)$ & 1065 & 85.8 \\
\hline$v(\mathrm{C} 6-\mathrm{C} 7), v(\mathrm{C} 7-\mathrm{C} 8)$ & 1055 & 9.5 \\
\hline$v(\mathrm{C} 11-\mathrm{O} 10)$ & 1050 & 41.0 \\
\hline$v(\mathrm{C} 12-\mathrm{C} 14)$ & 1023 & 22.2 \\
\hline$\gamma(\mathrm{N} 15-\mathrm{H})$ & 953 & 5.5 \\
\hline$\delta(C-C-C)$ indole & 879 & 11.2 \\
\hline$v(\mathrm{C} 12-013)$ & 867 & 23.4 \\
\hline$v(\mathrm{C} 16-\mathrm{C} 17), v(\mathrm{C} 16-\mathrm{C} 18)$ i.p. & 813 & 9.7 \\
\hline$\gamma(\mathrm{N} 15-\mathrm{H})$ & 780 & 54.0 \\
\hline Rings flipping chair & 764 & 3.8 \\
\hline$\gamma(\mathrm{C}-\mathrm{H})$ indole i.p. & 718 & 81.0 \\
\hline Rings breathing & 711 & 15.0 \\
\hline$\gamma(\mathrm{C} 2-\mathrm{H}), \gamma(\mathrm{C} 3-\mathrm{H})$ i.p. & 694 & 19.2 \\
\hline$\gamma(\mathrm{O} 13-\mathrm{H})$ & 403 & 119.0 \\
\hline
\end{tabular}

Abbreviations: a, anti-symmetric; s, symmetric; $\nu$, stretching; $\delta$, bending; $\omega$, wagging; tw, twisting; $\rho$ rocking; $\gamma$, bending out-of-plane; i.p., in-phase; o.p., outof-phase.

When two filled orbitals approach, there is a steric repulsion between them. A table of values corresponding to the destabilizing energy, $E_{i j}^{s t}$, between $i$ and $j$ pairs of filled orbitals is also given by the program.

The sum of the values found for $E_{i j^{*}}^{(2)}$ for the single point structures is $4408 \mathrm{~kJ} \mathrm{~mol}^{-1}$ and that for the optimized structure is $4230 \mathrm{~kJ} \mathrm{~mol}^{-1}$. In turn, the sums of the values obtained for the pair- 

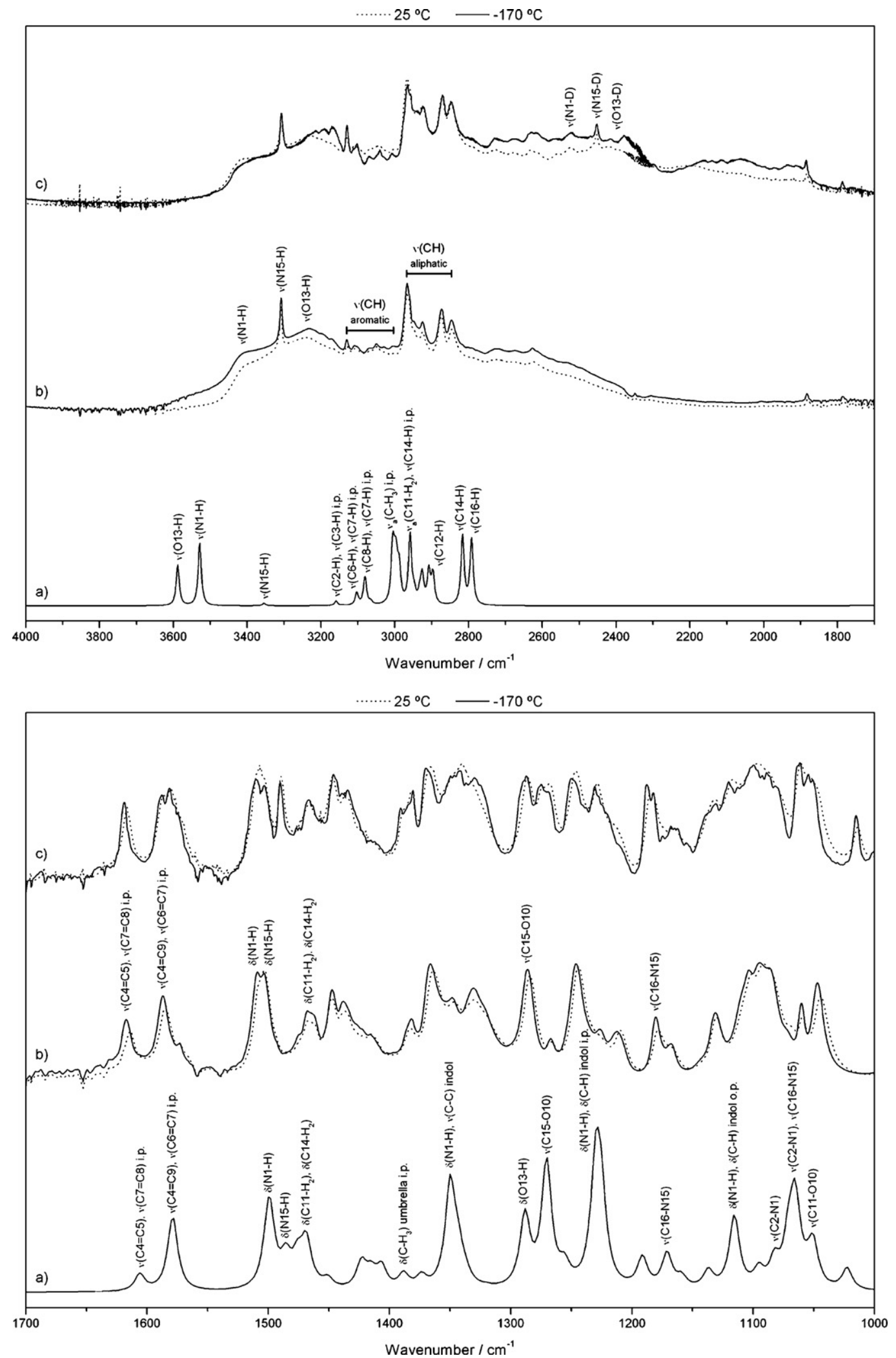

Fig. 2. Infrared spectra of pindolol before deuteration (b); and after deuteration (c) at $25^{\circ} \mathrm{C}$ and $-170^{\circ} \mathrm{C}$. The calculated spectrum is shown in (a). 


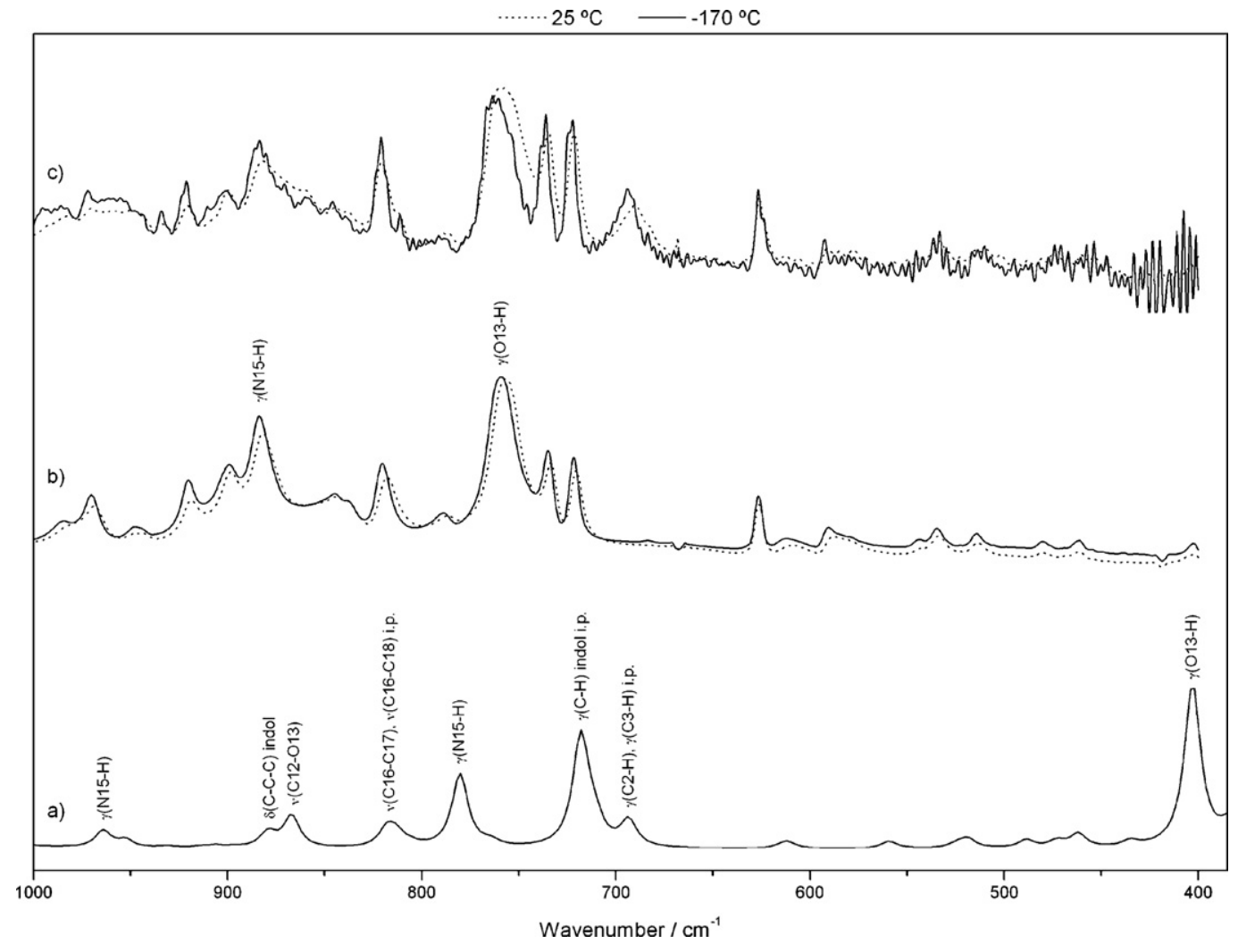

Fig. 2. (Continued).

wise steric repulsion $E_{i j}^{s t}$ are 2180 and $2127 \mathrm{~kJ} \mathrm{~mol}^{-1}$ for single point and optimized structures, respectively. That is a very high stabilizing effect results from the NBO interactions.

The results obtained for NBO analysis will be introduced during the discussion where they help elucidate structural features or spectral patterns.

\section{Results and discussion}

The experimental and calculated spectra of pindolol are presented in Fig. 2. The assignment of the bands for the calculated spectrum can be found in Table 1, and for the solid in Table 2.

Table 2

FTIR spectra of pindolol. Band description and wavenumbers $\left(\mathrm{cm}^{-1}\right)$.

\begin{tabular}{lc}
\hline Description & $\bar{v} / \mathrm{cm}^{-1}$ \\
\hline$\nu(\mathrm{N} 1-\mathrm{H})$ & 3404 \\
$\nu(\mathrm{N} 15-\mathrm{H})$ & 3309 \\
$\nu(\mathrm{O} 13-\mathrm{H})$ & 3258 \\
$\nu(\mathrm{C}-\mathrm{H})$ aromatic & $3136-3004$ \\
$\nu(\mathrm{C}-\mathrm{H})$ aliphatic & $2966-2844$ \\
$\nu(\mathrm{C} 14-\mathrm{H})$ & 2874 \\
$\nu(\mathrm{C} 16-\mathrm{H})$ & 2844 \\
$\nu(\mathrm{C} 4=\mathrm{C} 5), \nu(\mathrm{C} 7=\mathrm{C} 8)$ i.p. & 1617 \\
$\nu(\mathrm{C} 4=\mathrm{C} 9), \nu(\mathrm{C} 6=\mathrm{C} 7)$ i.p. & 1587 \\
$\delta(\mathrm{N} 1-\mathrm{H})$ & 1509 \\
$\delta(\mathrm{N} 15-\mathrm{H})$ & 1504 \\
$\delta\left(\mathrm{C} 11-\mathrm{H}_{2}\right), \delta\left(\mathrm{C} 14-\mathrm{H}_{2}\right)$ & 1468 \\
$\delta(\mathrm{C} 15-\mathrm{O} 10)$ & 1286 \\
$\nu(\mathrm{C} 16-\mathrm{N} 15)$ & 1180 \\
$\gamma(\mathrm{N} 15-\mathrm{H})$ & 883 \\
$\gamma(\mathrm{O} 13-\mathrm{H})$ & 759
\end{tabular}

Abbreviations: $\nu$, stretching; $\delta$, bending in-plane; $\gamma$, bending out-of-plane; i.p., inphase.

\section{1. $4000-1700 \mathrm{~cm}^{-1}$ region}

The spectral region between 4000 and $1700 \mathrm{~cm}^{-1}$ is a very important one as it is where the bands corresponding to the stretching vibration of $\mathrm{XH}(\mathrm{X}=\mathrm{N} 1, \mathrm{~N} 15, \mathrm{O} 13)$ are localized. These groups play a fundamental role in the structural organisation of the compound under study in condensed matter states due to their capacity to establish intermolecular hydrogen bonding. In addition to the vibrational modes of these groups, the $\mathrm{CH}$ stretch is also found in this spectral region.

From observation of the spectral pattern of the $\mathrm{XH}$ groups, one can see that $\mathrm{O} 13-\mathrm{H} 28, \mathrm{~N} 1-\mathrm{H} 19$ and N15-H31 stretching bands are well separated in the calculated spectra and strongly overlap and shifted to lower frequencies in the spectrum of the solid. Both effects are consequences of the hydrogen bonds involving these groups. In fact, this type of interaction shifts the band maximum towards lower frequencies, and increases both the band width and the integral intensity. The submaximum and subminima shown by the band contour enable us to determine the overlapping bands by peak fit analysis [12]. Using Gaussian and Lorentzian functions, the decomposition of the infrared spectra of the solid pindolol at $25^{\circ} \mathrm{C}$ gives the band components shown in Fig. 3. The main features of these bands (maximum position, half-height-width, maximum height and area percentage) are given in Table 3.

On deuteration, those bands move to 2525,2454 and $2422 \mathrm{~cm}^{-1}$, corresponding to the isotopic ratio of 1.35 , in agreement with the theoretical values obtained for the calculated spectra upon changing the hydrogen atom by deuterium.

On the basis of geometrical parameters, the main intermolecular interaction in the solid pindolol is a hydrogen bonding network involving the three polar groups [5]. The strength of these bonds follows the order: $\mathrm{O} 13-\mathrm{H} 28 \cdots \mathrm{N} 15>\mathrm{N} 1-\mathrm{H} 19 \cdots \mathrm{O} 13>\mathrm{N} 15-\mathrm{H} 31 \ldots \mathrm{O} 10$. Following the arguments given above, the assignment presented in Table 3 was established. 


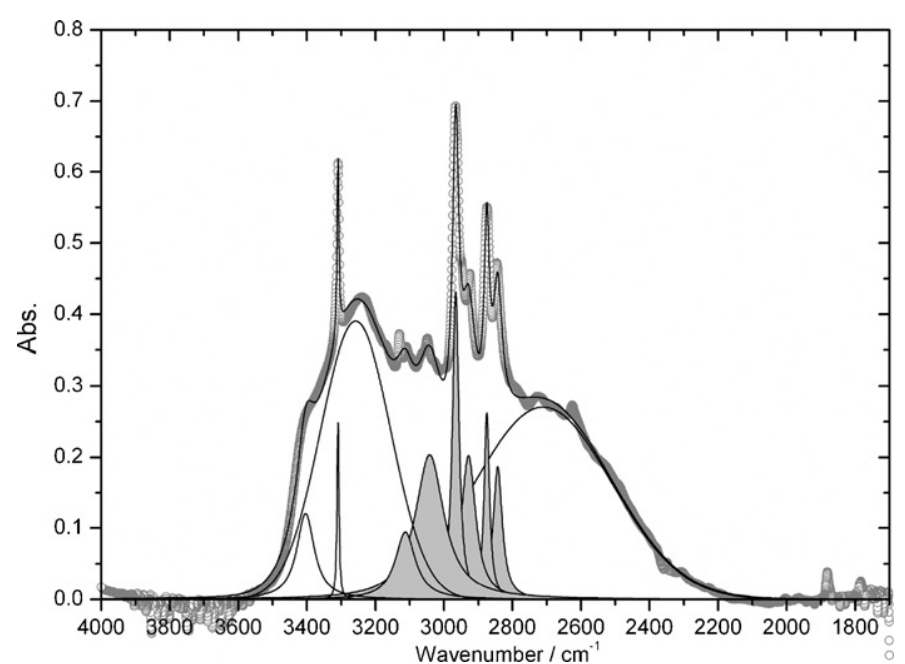

Fig. 3. Decomposition of the pindolol spectrum at $25^{\circ} \mathrm{C}$ in $4000-1700 \mathrm{~cm}^{-1}$. For a clear reading the $\mathrm{CH}$ stretch vibrations are filled curves.

The stretch band shift is commonly used to quantify the strength of hydrogen bonds [13-15]. As explained in Section 1, the shift in this paper is evaluated relative to the calculated spectrum. However, we have to be sure that the shift obtained in this way is due exclusively to the intermolecular interaction. Looking carefully at the calculated spectra we can see that $v(013-\mathrm{H} 28)$ occurs at a lower wavenumber than that assigned to the free group. In fact, the value found for the $013-\mathrm{H} 28$ stretching vibration in pindolol conformers in which no intramolecular interaction exists is $3611 \mathrm{~cm}^{-1}$ [16] which is in agreement with the value for alkyl alcohols $[13,17]$. If this internal bond persists in the solid, then the value given in the calculated spectra $\left(3588 \mathrm{~cm}^{-1}\right)$ is a correct reference for evaluating the intermolecular interaction; if this is not the case, it would be best to use that corresponding to the free group $\left(3611 \mathrm{~cm}^{-1}\right)$. To clarify this point we have applied the NBO
Table 3

Peak fit parameters of $\mathrm{OH}$ and $\mathrm{NH}$ stretch bands.

\begin{tabular}{lclcl}
\hline $\bar{v}_{\text {max }} / \mathrm{cm}^{-1}$ & $\begin{array}{l}\text { Width at half } \\
\text { height } / \mathrm{cm}^{-1}\end{array}$ & $\begin{array}{l}\text { Maximum } \\
\text { height/a.u. }\end{array}$ & $\begin{array}{l}\text { Relative } \\
\text { intensity/\% }\end{array}$ & Assignment \\
\hline 3404 & 62 & 0.12 & 3 & $\nu(\mathrm{N} 1-\mathrm{H})$ \\
3309 & 6 & 0.25 & 1 & $\nu(\mathrm{N} 15-\mathrm{H})$ \\
3258 & 242 & 0.39 & 30 & $\nu(\mathrm{O} 13-\mathrm{H})$ \\
3113 & 71 & 0.09 & 3 & \\
3042 & 101 & 0.20 & 9 & \\
2966 & 22 & 0.43 & 4 & \\
2928 & 50 & 0.20 & 5 & \\
2875 & 19 & 0.26 & 2 & \\
2843 & 32 & 0.19 & 3 & \\
2711 & 471 & 0.27 & 40 & \\
\hline
\end{tabular}

analysis to the single point and to the optimized structures. In NBO terms, the hydrogen bond under consideration corresponds to the stabilizing interaction $\mathrm{n}\left(\mathrm{LP}_{2} \mathrm{O} 10\right) \rightarrow \sigma^{*}(\mathrm{O} 13-\mathrm{H} 28)$. The values of $E_{i j^{*}}^{(2)}$ obtained in the optimized and single point structures are -2 and $-1 \mathrm{~kJ} \mathrm{~mol}^{-1}$, respectively. The PNBO overlaps of the orbitals involved in this interaction are depicted in Fig. 4.

The energy and the overlaps show that the optimized structure exhibits an intramolecular hydrogen bond which becomes vanishingly weak in the solid. This conclusion is further reinforced by the directionality of the $\mathrm{O} 13$ hybrid with respect to the $\mathrm{O} 13-\mathrm{H} 28$ bond. In the fully optimized structure, this hybrid is deviated $5.7^{\circ}$ from the line of the two nuclear centers while in the single point structure no significant deviation is observed. That is, the attraction of $\mathrm{H} 28$ towards the $\mathrm{O} 10$ atom turns $\mathrm{O} 13-\mathrm{H} 28$ into a slightly bent NBO.

Considering that the $013-\mathrm{H} 28 \ldots 010$ intramolecular hydrogen bond is very weak in the solid and increases in the optimized structure, we believe the reference wavenumber for the free $\mathrm{O} 13-\mathrm{H} 28$ group will be $3611 \mathrm{~cm}^{-1}$.

Another feasible intramolecular hydrogen bond in solid pindolol is $\mathrm{N} 15-\mathrm{H} 31 \ldots \mathrm{O} 13$. As can be seen from Table 4, the geometric data indicate the possibility of a weak hydrogen bond between these groups. These data are within the limits accepted for the existence
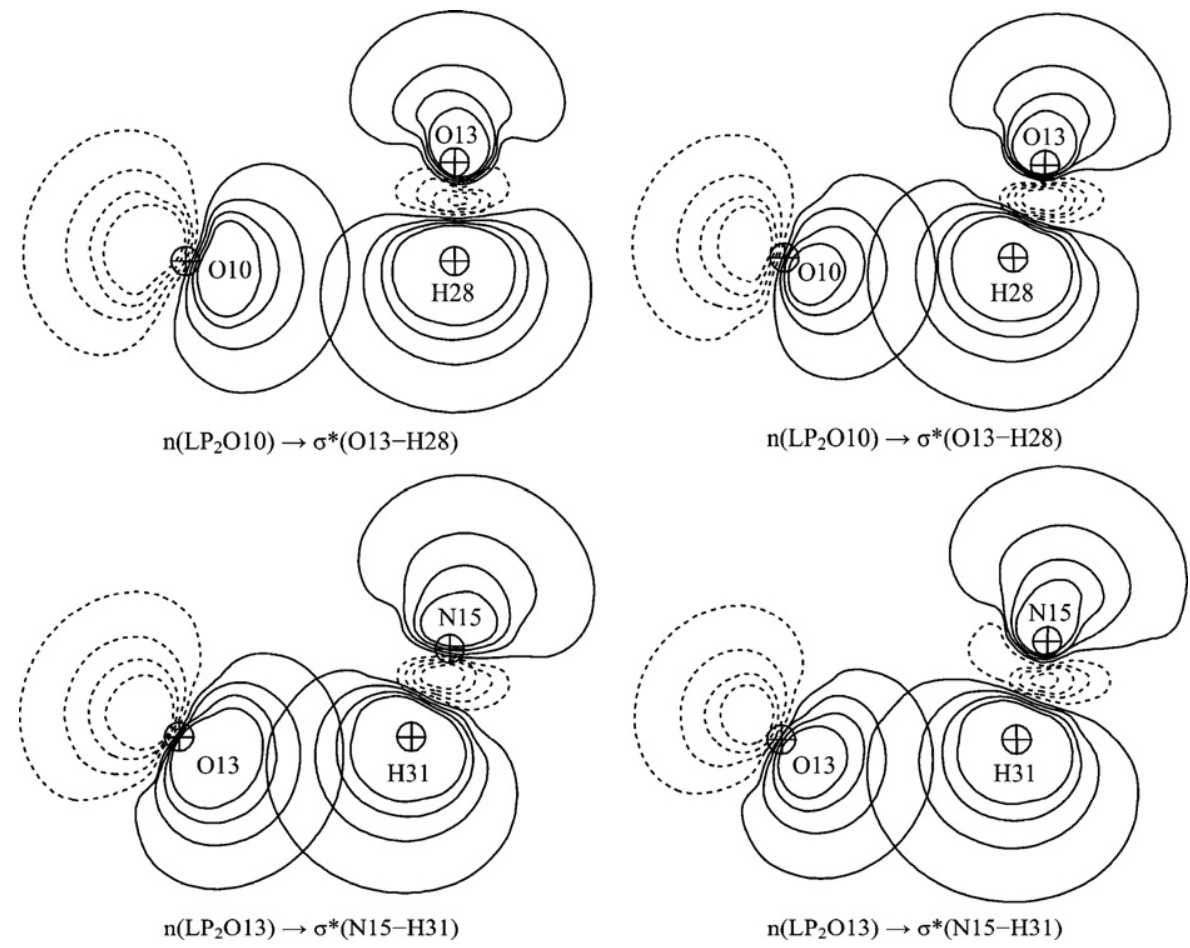

Fig. 4. PNBOs orbital overlap for $\mathrm{n}\left(\mathrm{LP}_{2} \mathrm{O} 10\right) \rightarrow \sigma^{*}(\mathrm{O} 13-\mathrm{H} 28)$ and $\mathrm{n}\left(\mathrm{LP}_{2} \mathrm{O} 13\right) \rightarrow \sigma^{*}(\mathrm{~N} 15-\mathrm{H} 31)$, left panel (single point structure), and right panel (optimized structure). 
Table 4

X-ray diffraction data for pindolol [5], and bond enthalpy.

\begin{tabular}{|c|c|c|c|c|c|}
\hline Hydrogen bond $(\mathrm{D}-\mathrm{H} \cdots \mathrm{A})$ & $\mathrm{D} \cdots \mathrm{A} / \AA ̊$ & $\mathrm{H} \cdots \mathrm{A} / \AA ̊$ & $\mathrm{D}-\mathrm{H} \cdots \mathrm{A} / /^{\circ}$ & $\Delta v / \mathrm{cm}^{-1}$ & $-\Delta H / \mathrm{kJ} \mathrm{mol}^{-1}$ \\
\hline 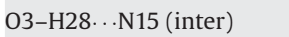 & $2.748(2)$ & $1.78(3)$ & $172(3)$ & 353 & 25 \\
\hline $\mathrm{N} 1-\mathrm{H} 19 \ldots \mathrm{O} 3$ (inter) & $2.858(3)$ & $2.03(4)$ & $156(3)$ & 125 & 13 \\
\hline N15-H31 ...010 (inter) & $3.355(3)$ & $2.98(3)$ & $106(2)$ & 45 & 3 \\
\hline O13-H28 ...010 (intra) & $2.841(2)$ & $2.66(3)$ & $91(2)$ & & \\
\hline N15-H31 ...013 (intra) & $2.821(2)$ & $2.31(3)$ & $114(2)$ & & \\
\hline
\end{tabular}

Table 5

Stabilizing energies and bond bending for single point and optimized structures.

\begin{tabular}{|c|c|c|c|c|c|}
\hline \multirow[t]{2}{*}{ Electron donor } & \multirow[t]{2}{*}{ Electron aceptor } & \multicolumn{2}{|l|}{ Single point } & \multicolumn{2}{|l|}{ Optimized } \\
\hline & & $E_{i j^{*}}^{(2)} / \mathrm{kJ} \mathrm{mol}^{-1}$ & First hydrib deviation $/^{\circ}$ & $E_{i j^{*}}^{(2)} / \mathrm{kJ} \mathrm{mol}^{-1}$ & First hydrib deviation $/^{\circ}$ \\
\hline $\begin{array}{l}\mathrm{n}\left(\mathrm{LP}_{1} \mathrm{O} 13\right) \\
\mathrm{n}\left(\mathrm{LP}_{2} \mathrm{O} 13\right)\end{array}$ & $\sigma^{*} \mathrm{C} 12-\mathrm{H} 27$ & $\begin{array}{l}13.2 \\
11.7\end{array}$ & 4.2 & $\begin{array}{r}6.8 \\
23.3\end{array}$ & 3.5 \\
\hline $\begin{array}{l}\mathrm{n}\left(\mathrm{LP}_{2} \mathrm{O} 13\right) \\
\mathrm{n}(\mathrm{LPN} 15)\end{array}$ & $\begin{array}{l}\sigma^{*} \mathrm{C} 12-\mathrm{H} 27 \\
\sigma^{*}{ }_{\mathrm{C} 14-\mathrm{H} 29}\end{array}$ & $\begin{array}{r}11.7 \\
9.6\end{array}$ & 2.7 & $\begin{array}{r}23.3 \\
7.9\end{array}$ & 1.9 \\
\hline n(LPN15) & $\sigma^{*} \mathrm{C} 14-\mathrm{H} 30$ & 23.8 & 1.5 & 33.6 & 2.6 \\
\hline n(LPN15) & $\sigma^{*} \mathrm{C} 16-\mathrm{H} 32$ & 35.4 & 7.9 & 31.2 & 2.1 \\
\hline
\end{tabular}

of such bonds [18]. Following the ideas discussed above we need to compare the parameters related to this hydrogen bond in the structure of the solid with that of the isolated molecule. The NBO analysis indicates that the hydrogen bond, $\mathrm{N} 15-\mathrm{H} 31 \ldots \mathrm{O} 13$ exists in both structures, and is stronger in the solid than in the isolated molecule. The values obtained for $E_{i j^{*}}^{(2)}$ are -5 and $-3 \mathrm{~kJ} \mathrm{~mol}^{-1}$ for single point and optimized structures, respectively. The PNBO overlaps corresponding to this interaction in both structures are given in Fig. 4 . As the intramolecular bond is present in both structures, the shift of the stretching vibration of the N15-H31 group was estimated relative to the calculated wavenumber $\left(3354 \mathrm{~cm}^{-1}\right)$.

On structural grounds, N1-H19 cannot be involved in an internal hydrogen bond. Thus, the reference wavenumber for estimating the intermolecular interactions involving this group is $3529 \mathrm{~cm}^{-1}$, a figure within the wavenumber interval defined by the values given in literature for indole [13,19].

Using the Iogansen [13] empirical relationship between the band maximum shift and the hydrogen bond enthalpy, the values obtained for this thermodynamic quantity are given in Table 4 .

The next spectral region to be interpreted is that between 3200 and $3000 \mathrm{~cm}^{-1}$ in which the bands correspond to the $\mathrm{C}-\mathrm{H}$ stretch vibrations of the indole group. The NBO analysis shows that the $\mathrm{C}-\mathrm{C}, \mathrm{C}-\mathrm{N}, \mathrm{C}-\mathrm{H}$ and $\mathrm{N}-\mathrm{H}$ bonds in the indole ring are approximately $\mathrm{sp}^{2}$ hybrids, and that the electron delocalization is extended to the O10 atom. The stabilizing energy, $E_{i j^{*}}^{(2)}$, related to the $\pi \rightarrow \pi^{*}$ interactions, ranges from -59 to $-97 \mathrm{~kJ} \mathrm{~mol}^{-1}$ and that corresponding to the interactions between the $\mathrm{n}(\mathrm{LPN} 1)$ and $\mathrm{n}\left(\mathrm{LP}_{2} \mathrm{O} 10\right)$ with the $\pi^{*}$ vicinal carbon atoms varies from -122 to $-151 \mathrm{~kJ} \mathrm{~mol}^{-1}$. Thus the indole group exhibits strong aromaticity, which assures to pindolol its specificity relative to other $\beta$-blockers.

The calculated spectrum shows five weak absorption bands corresponding to the in-phase coupling stretch modes of vicinal $\mathrm{C}-\mathrm{H}$ groups. The intensity of the out-of-phase bands is vanishingly weak. The $\mathrm{C}-\mathrm{H}$ stretching band maxima decreases with increasing $\mathrm{s}$ character of the carbon hybrid. Indeed, for the $\mathrm{C} 2-\mathrm{H} 20$ and $\mathrm{C} 3-\mathrm{H} 21$ groups the carbon hybridization is close to $\mathrm{sp}^{2}$ and the corresponding stretching vibrations occur at higher wavenumbers than those observed for phenyl $\mathrm{C}-\mathrm{H}$ groups in which the carbon hybridization varies from $\mathrm{sp}^{2.30}$ to $\mathrm{sp}^{2.42}$.

The spectrum of the solid corresponding to the $\mathrm{C}-\mathrm{H}$ stretch of the aromatic ring is in the same region as that of the calculated spectra, although the strong overlap prevents band assignment.

The vibrational bands localized in the region $3000-2800 \mathrm{~cm}^{-1}$ correspond to the stretch of the aliphatic $\mathrm{C}-\mathrm{H}$ groups. Usually not much structural meaning is attributed to these vibration modes of the $\mathrm{C}-\mathrm{H}$ groups. However, in pindolol they reflect the orbital delocalization playing an important role in the stabilization of the torsional conformations. The theoretical spectrum shows a rather interesting behaviour with respect to the $\mathrm{C} 14-\mathrm{H}_{2}$ stretch (index under $\mathrm{H}$ stays for methylene). As a rule geminal $\mathrm{C}-\mathrm{H}$ groups exhibit a coupled stretching vibration mode. The calculated spectrum of pindolol shows the stretch mode of $\mathrm{C} 14-\mathrm{H} 29$ coupled in-phase with $\mathrm{C} 11-\mathrm{H}_{2}$ at $2959 \mathrm{~cm}^{-1}$ and that of $\mathrm{C} 14-\mathrm{H} 30$ gives rise to an independent band at $2816 \mathrm{~cm}^{-1}$. The decoupling is explained by the strong stabilizing interaction between $\mathrm{n}(\mathrm{LPN} 15)$ and $\sigma^{*}(\mathrm{C} 14-\mathrm{H} 30)$ antibonding orbital. The $\mathrm{N} 15$ and $\mathrm{O} 13$ lone pairs interact with vicinal $\mathrm{C}-\mathrm{H}$ groups influencing their vibrational modes. In Table 5 , the values of the stabilizing energy between these lone pairs acting as electronic donors and the $\mathrm{C}-\mathrm{H}$ antibond orbitals as acceptors are given for both single point and optimized structures. In the same table, the deviations of the carbon hybrids from the line of nuclear centers in the $\mathrm{C}-\mathrm{H}$ bonds are also included.

Two sets of overlapping bands, separated by a narrow wavenumber interval, are then observed. One includes C14-H30 and C16-H32

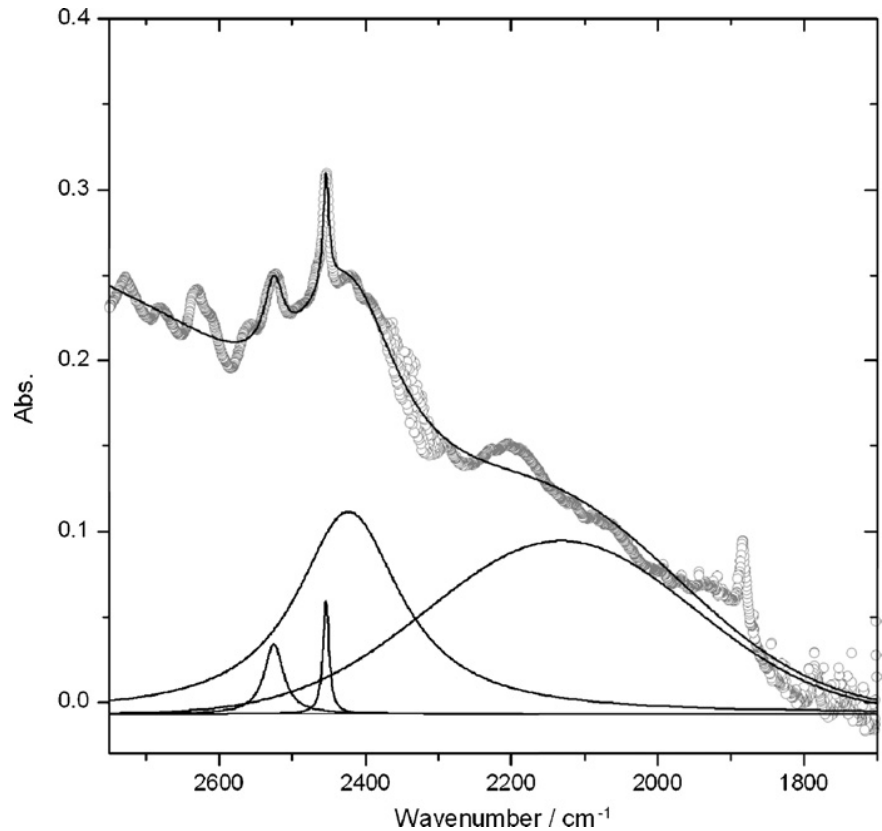

Fig. 5. Curve fit of the deuterated pindolol spectrum at $25^{\circ} \mathrm{C}$ between 2750 and $1700 \mathrm{~cm}^{-1}$. 
vibration bands, while the other corresponds to those of the remaining $\mathrm{C}-\mathrm{H}$ groups of the side chain.

In the region under consideration, the spectrum of the solid pindolol differs from the calculated one, firstly by an increase band width and consequently a strong overlap and, secondly, by a displacement of the band maxima towards higher wavenumbers. As a result of these NBO interactions a considerable deviation of the carbon hybrids is observed, in particular for the C16-H32 group in the single point structures.

The absorption of the solid pindolol between 2800 and $2200 \mathrm{~cm}^{-1}$ does not correspond to fundamental vibrational modes. Strong absorption in this region is frequently found in compounds containing, amide, amine or hydroxyl groups. Various theoretical approaches have been proposed based on the study of the spectra of dimers or oligomers of small size molecules [20-23]. Nevertheless, the Fermi resonance is the most popular interpretation for the absorption in this region. The anharmonic coupling of the stretching vibration of hydrogen bonded $\mathrm{NH}$ or $\mathrm{OH}$ and the first overtone of an in-plane bending or a combination band splits the fundamental band into two (Fig. 3). The maximum of one of these bands is displaced towards higher frequency and the other towards lower frequencies relative to the original band. Although the complexity of the Pindolol spectra one can see a strong band at $2661 \mathrm{~cm}^{-1}$ by curve fitting. Apparently, this band results from the coupling of stretching $\mathrm{OH}$ with an overtone in-plane bending vibration or combination mode. Since the Fermi effect requires that both fundamental and non-fundamental modes have a very close frequency the wavenumber of the latter should be approximately $1450 \mathrm{~cm}^{-1}$. Because of the large number of bands that can lead to overtones in this frequency range and the number of binary combinations able to do so it is not possible to provide a reliable identification of the modes involved.

The specie described as deuterated is in reality the partially deuterated compound. The simultaneous presence of deuterated and non-deuterated groups makes the spectral interpretation more difficult. However, important information can be drawn from it. In fact the H/D exchange allows the assignment of the stretching vibration of the polar groups. Another valuable piece of data concerns the absorption of the deuterated form in the $2750-1700 \mathrm{~cm}^{-1}$ region. Comparison between the spectra of the solid before and after deuteration shows further a strong absorption at approximately $2130 \mathrm{~cm}^{-1}$ for the deuterated form. The peak fit of the spectra between 2750 and $1700 \mathrm{~cm}^{-1}$ (Fig. 5) shows that Fermi resonance occurs between the fundamental O-D stretching vibration and bending in-plane bands similar to the effect found for the non-deuterated solid.

\section{2. $1700-1000 \mathrm{~cm}^{-1}$ region}

The $1700-1000 \mathrm{~cm}^{-1}$ region corresponds to $\mathrm{C}-\mathrm{H}, \mathrm{O}-\mathrm{H}, \mathrm{N}-\mathrm{H}$ inplane bending vibrations and to the stretch of the bonds between heavy atoms, in particular $\mathrm{C}=\mathrm{C}, \mathrm{C}-\mathrm{C}, \mathrm{C}-\mathrm{OH}, \mathrm{C}-\mathrm{O}$ and $\mathrm{C}-\mathrm{NH}$. The number of bands, the effect of intermolecular interaction in the vibrational modes and the strong vibrational coupling makes band assignment difficult for the experimental spectra in this region. However, some characteristic bands included in Table 2 have been identified by making use of the calculated and the deuterated spectra.

\section{3. $1000-400 \mathrm{~cm}^{-1}$ region}

The out-of-plane bending provides valuable information about the N15-H31 and 013-H28 groups. The most intense band of the first group in the theoretical spectra is observed at $780 \mathrm{~cm}^{-1}$. The substitution of the hydrogen by deuterium moves the band to $\bar{v}_{\max }=638 \mathrm{~cm}^{-1}$. In the spectrum of the solid this vibration mode is observed at $\bar{\nu}_{\max }=883 \mathrm{~cm}^{-1}$ and is shifted by deuteration to $690 \mathrm{~cm}^{-1}$.

The out-of-plane $013-\mathrm{H} 28$ vibration is seen at $403 \mathrm{~cm}^{-1}$ in the calculated spectra. In the solid the band corresponding to this vibrational mode occurs at $759 \mathrm{~cm}^{-1}$. On deuteration this band disappears.

\subsection{Temperature effect}

The influence of the temperature on the infrared spectra can be used to evidence hydrogen bonding interactions. The temperature effect has been interpreted on the grounds that the hydrogen bond gets stronger at lower temperatures [24,25]. The comparison between the spectra of pindolol at 25 and $-170{ }^{\circ} \mathrm{C}$ (Fig. 2) shows a displacement of the maximum of the bands corresponding to the donor groups of hydrogen bonds. The frequency of the stretching vibration modes of $\mathrm{N} 1-\mathrm{H}, \mathrm{N} 15-\mathrm{H}$ and $\mathrm{O} 13-\mathrm{H}$ decreases from 25 to $-170^{\circ} \mathrm{C}, 52,1$ and $41 \mathrm{~cm}^{-1}$, respectively.

The red shift due to temperature decreasing is the rule followed by $\mathrm{N} 1-\mathrm{H}$ and $\mathrm{O} 13-\mathrm{H}$. The $\mathrm{N} 15-\mathrm{H}$ is involved in a weak intermolecular hydrogen bond as acceptor and simultaneously in an intramolecular hydrogen bond as donor. Since the intramolecular interaction is not affected by temperature no displacement of the band due to this group is observed.

The maximum of supernumerary band due to Fermi resonance is displaced from 2711 to $2678 \mathrm{~cm}^{-1}$ as temperature varies from 25 to $-170^{\circ} \mathrm{C}$. Contrary to the stretching, the in-plane and out-ofplane vibration modes of the polar groups are displaced to higher frequencies as the temperature decreases [26].

\section{Conclusions}

Infrared spectroscopy provides relevant information on the intra- and intermolecular interactions in pindolol. The vibrational spectrum calculated for the conformation obtained from X-ray diffraction data reveals the effects of intramolecular hydrogen bonds and other types of interaction present in the isolated conformer. Based on the band maxima shifts, and from the spectrum of the solid, it is possible to quantify the intermolecular hydrogen bonds.

NBO theory provides an excellent approach to interpret the infrared spectra in electronic terms. Relative band positions, together with displacement of bands corresponding to molecular groups not involved in hydrogen bonds, are explained by this theory.

In this paper, NBO analysis was also used to evaluate the influence of the intermolecular interactions by comparing the results obtained for the single point and optimized structures.

\section{Acknowledgment}

Sandra C. C. Nunes acknowledges Fundação para a Ciência e a Tecnologia (FCT), Lisbon, for financial support. Grant SFRH/BD/1902/2004.

\section{References}

[1] J. Lopez-Sendon, K. Swedberg, J. McMurray, J. Tamargo, A.P. Maggioni, H. Dargie, M. Tendera, F. Waagstein, J. Kjekshus, P. Lechat, C. Torp-Pedersen, Eur. Heart J. 25 (2004) 1341.

[2] A.J. Kaumann, P. Molenaar, Pharmacol. Ther. 118 (2008) 303.

[3] J. Meier, Am. Heart J. 104 (1982) 364.

[4] C.A.S. Bergström, U. Norinder, K. Luthman, P. Artursson, Pharm. Res. 19 (2002) 182.

[5] T.K. Chattopadhyay, R.A. Palmer, D. Mahadevan, J. Chem. Crystallogr. 25 (1995) 195.

[6] A.D. Becke, J. Chem. Phys. 98 (1993) 5648.

[7] C.T. Lee, W.T. Yang, R.G. Parr, Phys. Rev. B: Condens. Matter 37 (1988) 785. 
[8] M.J. Frisch, G.W. Trucks, H.B. Schlegel, G.E. Scuseria, M.A. Robb, J.R. Cheeseman, J.J.A. Montgomery, T. Vreven, K.N. Kudin, J.C. Burant, J.M. Millam, S.S. Iyengar, J. Tomasi, V. Barone, B. Mennucci, M. Cossi, G. Scalmani, N. Rega, G.A. Petersson, H. Nakatsuji, M. Hada, M. Ehara, K. Toyota, R. Fukuda, J. Hasegawa, M. Ishida, T. Nakajima, Y. Honda, O. Kitao, H. Nakai, M. Klene, X. Li, J.E. Knox, H.P. Hratchian, J.B. Cross, V. Bakken, C. Adamo, J. Jaramillo, R. Gomperts, R.E. Stratmann, O Yazyev, A.J. Austin, R. Cammi, C. Pomelli, J.W Ochterski, PY, Ayala, K. Morokuma, G.A. Voth, P. Salvador, J.J. Dannenberg, V.G. Zakrzewski, S. Dapprich, A.D. Daniels, M.C. Strain, O. Farkas, D.K. Malick, A.D. Rabuck, K. Raghavachari, J.B. Foresman, J.V. Ortiz, Q. Cui, A.G. Baboul, S. Clifford, J. Cioslowski, B.B. Stefanov, G. Liu, A. Liashenko, P. Piskorz, I. Komaromi, R.L. Martin, D.J. Fox, T. Keith, M.A. Al-Laham, C.Y. Peng, A. Nanayakkara, M. Challacombe, P.M.W. Gill, B. Johnson, W. Chen, M.W. Wong, C. Gonzalez, J.A. Pople, Gaussian 03W, Revision D. 01, Gaussian Inc., Wallingford, CT, 2004.

[9] J.B. Foresman, Frish Exploring Chemistry with Electronic Structure Methods, 2nd ed., Gaussian Inc., Pittsburgh, PA, 1996.

[10] R. DenningtonII, T. Keith, J. Millam, GaussView, Version 4. 1. 2, Semichem Inc., Shawnee Mission, KS, 2007.

[11] E.D. Glendening, J.K. Badenhoop, A.E. Reed, J.E. Carpenter, J.A. Bohmann, C.M. Morales, F. Weinhold, NBO 5.0, Theoretical Chemistry Institute, University of Wisconsin, Madison, 2001.
[12] Microcal_Software, Peak Fitting Module 7.0, Origin ${ }^{\circledR}$ (version 7.03), OriginLab Corporation, copyright ${ }^{\complement} 1991-2002$.

[13] A.V. Iogansen, Spectrochim. Acta A 55 (1999) 1585

[14] A.A. Stolov, M.D. Borisover, B.N. Solomonov, J. Phys. Org. Chem. 9 (1996) 241

[15] R.M. Badger, S.H. Bauer, J. Chem. Phys. 5 (1937) 839.

[16] S.C.C. Nunes, A.J.L. Jesus, M.T.S. Rosado, M.E.S. Eusebio, J. Mol. Struct (THEOCHEM) 806 (2007) 231.

[17] D.L. Pavia, G.M. Lampman, G.S. Kriz, Introduction to Spectroscopy, 3rd ed., Harcourt College, Philadephia, 2001.

[18] T. Steiner, Angew Chem. Int. Ed. 41 (2002) 48.

[19] N. Sundaraganesan, H. Umamaheswari, B. Dominic Joshua, C. Meganathan, M. Ramalingam, J. Mol. Struct. (THEOCHEM) 850 (2008) 84.

[20] J. Edler, P. Hamm, J. Chem. Phys. 119 (2003) 2709.

[21] J. Edler, P. Hamm, Phys. Rev. B: Condens. Matter 69 (2004).

[22] H.T. Flakus, M. Chelmecki, Spectrochim. Acta A 58 (2002) 179

[23] H.T. Flakus, A. Tyl, P.G. Jones, Spectrochim. Acta A 58 (2002) 299.

[24] H.O. Desseyn, S.P. Perlepes, K. Clou, N. Blaton, B.J. Van der Veken, R. Dommisse P.E. Hansen, J. Phys. Chem. A 108 (2004) 5175

[25] H.O. Desseyn, K. Clou, R. Keuleers, R. Miao, V.E. Van Doren, N. Blaton, Spectrochim. Acta A 57 (2001) 231.

[26] M. Rozenberg, C. Jung, G. Shoham, Spectrochim. Acta A 61 (2005) 733. 